Final draft; for citation, please refer to the published version in: Leibniz and the Structure of Sciences, edited by Vincenzo de Risi, 271-298 (Berlin: Springer, 2019).

\title{
Teleology and Realism in Leibniz's Philosophy of Science
}

\begin{abstract}
This paper argues for an interpretation of Leibniz's claim that physics requires both mechanical and teleological principles as a view regarding the interpretation of physical theories. Granting that Leibniz's fundamental ontology remains non-physical, or mentalistic, it argues that teleological principles nevertheless ground a realist commitment about mechanical descriptions of phenomena. The empirical results of the new sciences, according to Leibniz, have genuine truth conditions: there is a fact of the matter about the regularities observed in experience.

Taking this stance, however, requires bringing non-empirical reasons to bear upon mechanical causal claims. This paper first evaluates extant interpretations of Leibniz's thesis that there are two realms in physics as describing parallel, self-sufficient sets of laws. It then examines Leibniz's use of teleological principles to interpret scientific results in the context of his interventions in debates in seventeenth-century kinematic theory, and in the teaching of Copernicanism. Leibniz's use of the principle of continuity and the principle of simplicity, for instance, reveal an underlying commitment to the truth-aptness, or approximate truth-aptness, of the new natural sciences. The paper concludes with a brief remark on the relation between metaphysics, theology, and physics in Leibniz.
\end{abstract}

\section{Introduction}

Among the signature features of Leibniz's mature philosophy is a commitment to a harmonious, teleological structure of reality. Bucking the trend of seventeenth-century mechanical philosophy, Leibniz attempts to reintroduce teleological notions of ends and final causes in natural science. Indeed, beyond separating the domains of mental and physical reasons, which are coordinated through a divinely instituted harmony, Leibniz further contends that there are "two kingdoms even in corporeal nature," and that mechanical laws "depend on more sublime principles" of order and wisdom. ${ }^{1}$ Teleological principles, thus, should be valid not just for describing mental acts of desiring or willing, but also for physical events of impact and collision.

\footnotetext{
1 “Tentamen anagogicum” (ca. 1696), GP VII 273; L 478-9.
} 
How precisely Leibniz understands the co-governance of nature by mechanical and teleological principles remains contested. It is one thing for Leibniz to recognize final causes as governing an order of mental events parallel to that of physical events, but an altogether different proposition to argue for teleology in the physical domain itself. For one thing, it appears flatly to violate his own firm contention, shared with many contemporaries, that we should explain "all the phenomena of physics mechanically." ${ }^{2}$ From his early conversion to the mechanistic view of nature, through his important contributions to mathematical physics over the next few decades, and into his later, monadological metaphysics, Leibniz remains committed to the search for mechanical causes as the goal of science. ${ }^{3}$ While we certainly cannot assume that Leibniz held fixed or unambiguous positions on many topics over the course of his life, the value he attaches to mechanical explanation remains constant. Given his firm commitment to the sufficiency of mechanism, what role does he think is left for teleology?

This essay identifies an autonomous place for classical teleological principles-roughly, variations on the old thesis that 'nature does nothing in vain'-in Leibniz's philosophy of physical science. It develops a reading of Leibniz as a scientific realist in which principles such as continuity and simplicity are indispensable. Specifically, I argue that Leibniz was committed to a thoroughgoing realism about the semantics of physical science: the claims of the new mechanical sciences of the seventeenth century, for Leibniz, have genuine truth conditions, or

\footnotetext{
2 "New System" (1695), GP IV 487; WF 22.

${ }^{3}$ Writing to Remond in 1714, he recounts his conversion to the new, mechanical philosophy in the 1660s: "After finishing the Écoles Triviales I fell upon the moderns, and I recall walking in a grove on the outskirts of Leipzig called Rosental, at the age of fifteen, and deliberating whether I should keep the substantial forms. Mechanism finally prevailed and led me to apply myself to mathematics" (G III 606; L 655). In 1678, during an intense period of work in physics and optics, he writes to Hermann Conring: "everything happens mechanically in nature, that is, according to certain mathematical laws prescribed by God" (A II.1 604; L 189). And to Burcher de Volder in 1703: "in phenomena... everything is explained mechanically" (GP II 250; L 529).
} 
aspire to give true descriptions of phenomena. It is in this sense that Leibniz's philosophy of science embeds semantic realism: when properly interpreted, theoretical statements about the physical world can be said to be true or false.

To be sure, the truth-aptness of scientific claims on the reading of Leibniz developed here does not consist in metaphysical truths at the fundamental level of ontology. For, at least by the last decade of his life, if not earlier, Leibniz espouses a sophisticated form of metaphysical idealism according to which "there is nothing in things except simple substances, and in them perceptions and appetites." ${ }^{\prime 4}$ For Leibniz, there is no non-mental reality as such. Whatever exists is either a mind (or a mind-like thing; in his later terminology, a monad), or a modification of one. On this picture, the material world of chairs and tables reduces to, or results from—-to use Leibniz's technical locution - the perceptions of quasi-spiritual beings. ${ }^{5}$ Consequently, the truthorientation proper to physical science, for Leibniz, is ultimately demarcated from the aims of metaphysics or morals, which seek their first principles through inner experience, or reflection

\footnotetext{
${ }^{4}$ Letter to de Volder, June 30, 1704, GP II 270; L 537.

${ }^{5}$ This view of the dependence of ordinary material objects on perceptions gives rise to the question of whether Leibniz can retain any place for material substance realism. The issue of the reality of material substances, however, should be kept apart from Leibniz's realism per se. For the ideality of Leibnizian monads does not make them unreal or illusory. On the idealist reading of Leibniz, minds are the most real beings; material bodies, meanwhile, are ontologically subordinate and thus are interpreted as having derivative reality. Readings of Leibniz as an idealist in this sense include Gueroult (1967), Adams (1994), Rutherford (1995), and De Risi (2007). Garber (1985) influentially challenged the idealist interpretation as a correct account of Leibniz's middle period, proposing instead a corporeal substance account on which bodies have reality independently of minds, and inspired others to develop broader, non-idealist readings of Leibniz. Phemister (2005), Hartz (2007), and McDonough (2016) are some of the authors to have followed Garber in defending readings of Leibniz as a material substance realist, where corporeal substances have an independent, foundational ontological status. In his 2009 Leibniz: Body, Substance, Monad, Garber responds to critics, but agrees that, by the Monadology period, Leibniz has embraced a metaphysical idealism on which minds and their experiences are the only ultimately real beings.
} 
on the thinking self. ${ }^{6}$ As Maria Rosa Antognazza has recently argued, "for Leibniz, physics proper is the study of natural phenomena in mathematical and mechanical terms without recourse for its explanations to metaphysical notions." At the same time, however, Leibniz recognizes that a physics unanchored in metaphysics would be seriously deficient. Antognazza continues that, the autonomy of physics "does not imply for Leibniz that physics can say on its own all that there is to be said about the natural world. Quite the opposite. Leibniz inherits from the Aristotelian tradition the view that physics needs metaphysical roots or a metaphysical grounding." ${ }^{.7}$ Leibniz's division between the metaphysical and the physical does not amount to a separation between a realm of inquiry guided by the epistemic value of truth and one guided by utility or convenience. Physical science aims at the truth as well, though in its own, properly delimited field of appearances.

In the absence of any mind-independent material reality as such, the truth or falsity of scientific claims ultimately rests in facts about the intersubjective contents of perceptions. Leibniz's realism does not aim to uphold common-sense intuitions about a reality independent of any perceiver whatsoever. But while the objects of knowledge are not mind-independent material bodies, they are also not mere illusions. For Leibniz, true concepts of physical objects possess fixed, univocal content, the explication of which constitutes the aim of science. This content consists in the descriptive terms and mathematical laws that express regularities among the

\footnotetext{
${ }^{6}$ To Thomas Burnet, for example, he writes: "Locke did not well understand the origin of necessary truths, which do not depend on the senses, or on experiences, or on facts, but on the consideration of the nature of the soul, which is a being, a substance, having unity, identity, action, passion, duration, etc. We need not be astonished if these ideas and the truths which depend on them are found in us, although we need reflection to perceive them, and sometimes need experiences to elicit our reflection or attention, to make us notice of what our own nature provides us" (26 May, 1706; G III, 307-308).

${ }^{7}$ Antognazza (2017, 21).
} 
objects of outer experience. Explicating this content, however, requires science to reach beyond the actual and possible observational evidence that would license belief in statements involving theoretical terms. Physical science, for Leibniz, must recognize certain non-empirical principles, those which posit unity, simplicity, and harmony in the phenomenal realm, as necessary conditions for the truth-aptness of its first-order, empirical claims. Truth conditions for theoretical statements are distinct from their verification conditions. To formulate truth conditions for an empirical claim commits us to recognizing normative epistemic principles for theory construction distinct from the facts which would confirm or disconfirm those claims. This condition on the truth-aptness of scientific claims brings with it teleological principles of harmony and orderliness in nature. ${ }^{8}$

Leibniz's view that the new physics requires teleology acquires its significance in this semantic context. Mechanical principles alone, according to Leibniz, provide inadequate support for a realist interpretation of theoretical terms and laws even when restricted to the domain of phenomena. A suite of non-empirical principles - such as the principle of continuity, the principle of maxima and minima, and the principle of simplicity—enter Leibniz's scientific work to interpret the data gathered from experiments and observation in models that aim to reconstruct the true order of appearances. On Leibniz's envisioned reconciliation of efficient and final causes, teleological principles are always at work in science. They serve a variety of necessary functions: they mediate the unification of empirical laws, guide choice between competing hypotheses, and inform the classification of natural kinds. In these roles, teleological principles are not merely heuristical. They do not simply provide an easier method for deducing physical

\footnotetext{
${ }^{8}$ The realism I attribute to Leibniz is similar to Psillos' (1999, 10-13) understanding of semantic realism, with the important caveat that Leibniz rejects the realist intuition of the mindindependence of theoretical entities.
} 
laws, or a convenient scheme for organizing experimental data, but are indispensable for interpreting empirical results as expressive of nature. In other words, on the reasonable supposition that the working scientist takes herself to be investigating the truth about nature, teleological principles inescapably figure as constraints on the semantics of any theory. Leibniz's defense of teleology in physics is motivated by a concern to articulate a realist interpretation of the new natural science of the seventeenth century. ${ }^{9}$

My strategy is as follows: Section Two spells out some possible meanings of Leibniz's thesis that there are two realms in physical nature. It suggests reasons why Leibniz seeks a deep unity of mechanical and teleological principles, such that each serves a distinct, necessary role in scientific explanation. Section Three discusses Leibniz's views on the aims of science in general, and identifies unification as a key virtue in his conception of explanation. Section Four elucidates the central claim of the paper by showing how teleological commitments to harmony, considered as a semantic notion of unity in diversity, figure in Leibniz's defense of heliocentrism. The essay concludes with some reflections on Leibniz's views on the relation between science and metaphysics (and theology).

\section{Two realms in corporeal nature}

Leibniz's various discussions on the place of teleology in natural science do not readily present a univocal position. In "Discourse on Metaphysics" (1686), for instance, Leibniz suggests a heuristical role for teleology: "The way of final causes... is easier [than the profounder way of

\footnotetext{
${ }^{9}$ My interpretation departs, accordingly, from François Duchesneau's, inasmuch as, on my view, Leibniz does not think that the justification of teleological principles consists in their utility or fecundity in explaining particular phenomena. I agree with Duchesneau, however, in that I see Leibniz as giving teleological principles a constitutive role in nature; see Duchesneau (1993, 260-2). I will return to Leibniz's deeper foundations for teleological reasons in the conclusion.
} 
efficient causes] and is often useful for understanding important and useful truths, which one would be a long time seeking by the other more physical route." ${ }^{10}$ By contrast, in notes from the late 1670 s, Leibniz suggests an explanatory equivalence of efficient and final causal laws: “All natural phenomena can be explained by final causes alone, just as if there were no efficient cause; and all natural phenomena can be explained by efficient causes alone, as if there were no final [cause]."11 A third view, expressed in the "Tentamen anagogicum" (1696), hints at distinct but complementary roles for efficient and final causes, such that, even if every natural fact were mechanically explicable, teleological reasons would still be required to ground mechanical principles: "all natural phenomena could be explained mechanically if we understood them well enough, but the principles of mechanics themselves cannot be explained geometrically, since they depend on more sublime principles which show the wisdom of the Author in the order and perfection of his work." ${ }^{\prime 2}$ Do these remarks admit of a single, consistent position concerning the status of teleological principles?

It is likely that Leibniz entertained several positions concerning natural teleology over the course of his multi-faceted career, and I won't attempt to force a uniquely correct view onto his corpus. That he does, on occasion, grant the heuristical value of teleological reasoning based on attributions of functions and goals, whether or not they are supported by causal mechanisms, is confirmed in other texts. Commenting on Descartes' Principles of Philosophy in 1692, for instance, Leibniz contends that, from the mere discovery of usefulness of some phenomenon, we can confidently infer the existence of a reason for it in God's mind. ${ }^{13}$ Certainly, such reasoning

\footnotetext{
${ }^{10}$ GP IV 448; L 317.

${ }^{11}$ A VI.4B 1403. The notes are titled "Definitiones cogitationesque metaphysicae" and dated by the Academy editors to $1678-80$.

12 GP VII 272; L 478.

${ }^{13}$ GP IV 360-1; L387.
} 
in the context of discovery is typically considered innocuous, and Leibniz offers examples of such useful, non-explanatory discoveries: "in the natural world... the discovery of the magnetic needle is and will be a great thing, even if its workings remain forever unexplained to us." ${ }^{14}$ Yet, this constitutes only the weakest respect in which Leibniz recognizes the validity of teleology.

The independent sufficiency of final causal explanations motivates the second of the interpretive options above, namely, that efficient and final causes constitute parallel laws of the physical world. The view ascribes to Leibniz a thesis of explanatory overdetermination, though of a unique sort. Overdetermination here is not captured in the standard example of two stones striking a window simultaneously — that sense of causal overdetermination remains within the realm of efficient causes. Rather, the equipotency of efficient and final causes is the thesis that the breaking of the window is determined independently by two different kinds of causes, so that every physical fact can, in principle, be sufficiently explained by either efficient causal or final causal laws. ${ }^{15}$ The main impetus for such a reading comes from Leibniz's work in optics. In fact, in each of the three texts cited in the opening paragraph of this section, Leibniz illustrates his defense of final causes by appeal to a derivation of the laws of reflection and refraction from an optimization principle. This result, already described by Pierre de Fermat earlier in the century, and repeated by Leibniz in his 1682 "Unicum opticae, catoptricae et dioptricae principium," demonstrates the two basic laws of optics - the law of reflection and the law of refraction-by using the principle that a ray of light always travels through the easiest path; or, stated more generally, that "nature, proposing some end to itself, chooses the optimal means."16 Employing

\footnotetext{
${ }^{14}$ Cited in Antognazza (2017, 36n).

${ }^{15}$ McDonough $(2008,2009,2010)$ defends such a reading. "Equipotency" is his term to describe the relation between laws of efficient and final causes $(2008,674)$.

${ }^{16}$ A VI.4B 1405.
} 
as a first hypothesis that "light irradiating from a point reaches an illuminated point by the easiest path," Leibniz's strategy is to use this principles alone to derive both the law of reflection-the equality of the angle of incidence and the angle of reflection — and the basic law of refractionthat the ratio of the sines of the angles of incidence and refraction is equivalent to the reciprocal of the ratio of the resistances of the media through which light passes. ${ }^{17}$ That Leibniz was very impressed with the result is evident from the numerous occasions on which he cites it in defense of final causes. ${ }^{18}$

Neither the laws nor their association with teleology is original with Leibniz. Already in Hellenistic times, Hero of Alexandria had formulated the problem of finding the angles of incidence and reflection under the teleological supposition that light strives to move over the shortest possible distance. ${ }^{19}$ The use of such principles continues to flourish in modern mathematical sciences, where they collectively comprise the variational calculus. The distinctive feature of variational principles is that they express the maximization or minimization of some physical quantity. Light rays minimize the time taken to travel between two points. The hexagonal cells of honeycombs maximize storage space per ounce of wax. The spherical shape assumed by a single drop of water minimizes the surface tension of water molecules. Such phenomena have struck some observers, from antiquity to today, to indicate an intrinsic proclivity in nature toward harmony. The strikingly contingent character of such arrangements have further suggested intentional activity that could effect such apparent coincidences through

\footnotetext{
${ }^{17}$ See McDonough $(2008 ; 2010)$ for a detailed reconstruction of Leibniz's procedure. McDonough's translation of Leibniz's text is available at http://philosophy.ucsd.edu/faculty/rutherford/Leibniz/unitary-principle.htm.

${ }^{18}$ Cf. GM VI 243, L 442; GP VII 274ff, L 480ff; LS 24-25.

${ }^{19}$ Lemons (1997, 13-14). See Darrigol (2012, ch1) for ancient and medieval Greek and Arabic precedents.
} 
advance knowledge of the optimal end state - the minimization of propagation time for light rays, the maximization of honey stores, the conservation of molecular energy. The variational procedure inverts the style of reasoning used in classical mechanics. Whereas a typical mechanical derivation - find the acceleration of a particle given inertial force and massrequires knowledge of initial conditions, variational principles demand boundary conditionsfind the shape of a drop of water such that surface tension is a minimum. The thesis of explanatory overdetermination proposes to treat this method of discovery as having independent sufficiency. ${ }^{20}$

There are multiple reasons for skepticism about a view that regards nature as lawfully overdetermined in this way. Attending to these problems motivates the third option identified above, namely, that, for Leibniz, efficient and final causes serve distinct but complementary functions in unified explanations.

In the first place, admitting two parallel laws of nature plainly violates the principle of parsimony. Despite the popular image of Leibniz as a flamboyant metaphysician, such a violation runs afoul of his express commitment to the old maxim not to multiply entities without necessity. Indeed, Leibniz frequently ties the principle of preferring the simpler hypothesis, or of maximizing effects from fewest causes, to the nature of divine wisdom. In "Discourse on Metaphysics", he writes of the divine act of creation that, "where wisdom is concerned, decrees or hypotheses are comparable to expenditures, in the degree to which they are independent of each other, for reason demands that we avoid multiplying hypotheses or principles." ${ }^{21}$ Similarly,

20 The question of the value of these forms of reasoning continues to be contested in contemporary philosophy of science. For recent defenses of the sufficiency of mathematical explanations of the sort rendered through variational principles, see Ginzburg and Colyvan (2004), Baker (2009), and Lange (2013).

${ }^{21}$ GP IV 431; L 306. 
in "On the Radical Origination of Things" (1697) Leibniz identifies the principle that "a maximum effect should be achieved with a minimum outlay" as a principle of what he admires as a "divine mathematics or metaphysical mechanism." 22 That God should decree two sets of laws to institute the same series of phenomena plainly contradicts this axiom of his wisdom. While Leibniz's God is indeed committed to creating as much being as possible, he is not thereby committed to multiplying ways of lawfully relating essences.

Second, the empirical adequacy of Leibniz's mathematical constructions for deriving the laws of optics does not license inferences about the physical causes governing the behavior of light. By the lights of Leibniz's own commitment to mechanical explanation, the causes for physical phenomena must be sought in the sizes, shapes, and motions of bodies. In this regard, Ernst Mach's criticism of formal teleological explanations in his Science of Mechanics (1883) is instructive. For Mach, the value of Fermat's, Leibniz's, or Maupertuis' method consists in its "economical character" and that "it secures us a practical mastery" of physical phenomena even though it provides no explanatory insight. ${ }^{23}$ The reason why teleological principles do not yield insight into physical processes, according to Mach, can be seen from a proper grasp of mechanical explanations. The observation that many phenomena express maximal or minimal quantities owes not to the tendency of nature to seek elegance or economy, but simply to the fact that, when the least or greatest possible physical magnitude has been reached, no further change is possible. A catenary - the shape assumed by a rope or chain when hanging from its ends and carrying only its own mass - reaches the lowest point of center of gravity, not because it seeks that point, but because further descent is impossible once the chain is in that state. The

\footnotetext{
22 GP VII 303-4; L 487-8.

${ }^{23}$ Mach $(1919,341)$.
} 
explanatory work here is performed by facts about the forces acting upon the chain when it is in a certain shape, not in nature's inclinations toward certain ends. Mach explains: "The important thing, therefore, is not the maximum or the minimum, but the removal of work; work being the factor determinative of the alteration." Endorsing a dispassionate sobriety in scientific matters, he concludes that: "It sounds much less imposing but is much more elucidatory, much more correct and comprehensive, instead of speaking of the economical tendencies of nature, to say: 'So much and so much only occurs as in virtue of the forces and circumstances involved can occur." 24 It is true that the principle of least time saves the phenomena of the relations among angles resulting from reflected and refracted light, but the empirical adequacy of the principle should not be mistaken for a causal explanation of the propagation of light.

Finally, there are compelling textual reasons for why Leibniz should not wish to be saddled with a view of the corporeal realm as governed by two parallel sets of laws. Part of Leibniz's dialectical objective of undercutting the Cartesian natural philosophers' rejection of teleology is to recover grounds for assent to a divinely instituted intelligibility in nature. His strategy to this end depends on his defense of the thesis that the laws of nature are contingent rather than necessary, as Descartes had maintained. That is, Leibniz argues that the laws of collision and impact, which impressively predict physical interactions, cannot themselves be grounded in more basic geometrical facts and, consequently, well-confirmed facts such as those expressed in the principle of the conservation of kinetic energy, or in the law of the equality of full cause with the full effect, cannot be demonstrated as logical or mathematical identities. ${ }^{25}$

\footnotetext{
${ }^{24}$ Mach $(1919,459-60)$

${ }^{25}$ Leibniz famously demonstrates, against Descartes, that it is not momentum (mv) but kinetic energy $\left(\mathrm{mv}^{2}\right)$, vis viva, that is conserved in collision events. For reasons of space, I cannot discuss any further Leibniz's reasons for holding conservation laws to be contingent, and
} 
What's lacking to adequately ground the new physics, Leibniz thinks, are further facts that would establish the necessitating, or law-like, character of the laws of motion. It is precisely this lawlikeness which, according to Leibniz, cannot be supplied through mechanical principles, but instead requires principles that he variously calls "metaphysical", "architectonic", or "laws of final causes". ${ }^{26}$ But Leibniz does not thereby wish to assert the absolute priority of final causes over efficient causes in physics either. Rather, it is crucial to recognize the legitimate role of each kind of principle. It is worth reviewing again what he wrote in the "Tentamen":

The true middle term for satisfying both truth and piety is this: all natural phenomena could be explained mechanically if we understood them well enough, but the principles of mechanics themselves cannot be explained geometrically, since they depend on more sublime principles which show the wisdom of the Author in the order and perfection of his work. ${ }^{27}$

Leibniz's goal in this conciliatory project is to emphasize the interconnection between the two kinds of principle, as opposed to securing their parallel coexistence. Knowledge of the mechanisms by which bodies operate and are produced is a central goal of physics, and it is axiomatic for him that we should seek complete mechanical descriptions of material phenomena. ${ }^{28}$ In an earlier, programmatic text on the methods and aims of natural philosophy,

therefore as, strictly speaking, outside a purely mathematical physics. In any case, this issue is well studied in the literature. See Garber (2009, ch.6) for a detailed account.

${ }^{26}$ GP VII 273; L 479.

${ }^{27}$ GP VII 272; L 478. He expresses this thought also in "Specimen dynamicum": "In my judgment the best answer, which satisfies piety and science alike, is to acknowledge that all phenomena are indeed to be explained by mechanical efficient causes but that these mechanical laws are themselves to be derived in general from higher reasons and that we thus use a higher efficient cause only to establish the general and remote principles" (GM VI 242; L 441).

${ }^{28}$ Leibniz insists on this virtually throughout his career. An unambiguous statement of it comes from the De Volder correspondence: "in phenomena... everything is explained mechanically" (GP II 250; L 529). It should also be borne in mind that for Leibniz the mechanistic principle 
the "Praefatio ad libellum elementorum physicae" (1678-79), Leibniz virtually identifies mechanical description with distinct explanation:

[T] he way in which a body operates cannot be explained distinctly unless we explain what its parts contribute. This cannot be understood, however, unless we understand their relation to each other and to the whole in a mechanical sense, that is, their figure and position, the change of this position or motion, their magnitude, their pores, and other things of this mechanical kind, for these always vary the operation. ${ }^{29}$

Leibniz emphasizes here the indispensability of mechanical explanations for the operations of bodies, implying that an explanation cast solely in terms of teleological principles could not displace an explanation of bodies in terms of the law-governed motions of their parts. The claim here is not that one merely has the option of explaining bodily occurrences through laws of motion and impact. Rather, natural scientists must seek quantitative expressions of the regularities among phenomena and their material bases.

At the same time, an adequate foundation for the science of mechanics requires metaphysical principles, which Leibniz attributes to God's rational volition to bring about an orderly course of nature. But while Leibniz is predictably critical in the "Tentamen" of the materialists and the necessitarians who exclude God's purposes from nature, he is equally critical of the "zealous theologians who, shocked at the corpuscular philosophy and not content with checking its misuse, have felt obliged to maintain there are phenomena in nature which cannot be explained by mechanical principles." Leibniz worries that, by replying in a dogmatic manner to

encompasses the biological realm as well. In the New Essays, for instance, he writes: "I attribute to mechanism everything which takes place in the bodies of plants and animals except their initial formation" (NE 139).

${ }^{29}$ A VI.4 2008; L 288. 
the excesses of the mechanical philosophy, the defenders of piety "injure religion in trying to render it a service. ${ }^{, 30}$ Whereas the mechanical philosophers fail to recognize the deeper grounding (in reasons rather than in arbitrary volitions) required by the laws of motion, their polemical opponents fail to appreciate the harmony of nature represented in the mechanical picture, which alone is worthy of a perfectly wise creator. A consistent feature of Leibniz's defense of the new physics is his conviction that the simplicity and generality of its laws is uniquely befitting of divine wisdom. A brute appeal to divine providence, a mere assertion that mechanical laws require further support without any account of how such metaphysical grounds interact with mechanical principles, does not do justice either to the cause of faith or to that of reason. The moral Leibniz wishes to impress is that neither a purely mechanistic nor an exclusively final causal approach suffices for a proper understanding of nature. The 'middle term' must be such as to form a link between the two, so that each kind of principle could be shown to be indispensable in a full account of the world. Leibniz, ultimately, wishes to place stronger constraints on what constitutes an adequate physical explanation than either the mechanists or the theists. A parallelism of two equipotent sets of laws would weaken those constraints by allowing each method to be sufficient on its own.

I submit that, like the heuristic reading, the equipotency reading also captures only a limited application of teleology in Leibniz's scientific work. The use of optimality principles to derive the laws of reflection and refraction provides only weak reasons for the kind of general validity of teleological principles in natural science that Leibniz seems to want. Leibniz, as suggested by the passage from the "Tentamen," accords a privileged role to final causes, inasmuch as they are required for efficient causes to have explanatory force. Put another way,

${ }^{30}$ GP VII 272; L 478. 
Leibniz's conception of the relation between final and efficient causes is one of complementarity — each dispenses a distinct, necessary function in explanation. Moreover, an independent sufficiency of mechanism and teleology does not sit comfortably with Leibniz's dialectical interest in their reconciliation. The deeper source of legitimacy for teleological principles accrues from their role in the construction and interpretation of scientific theories.

\section{Teleology and scientific realism}

Although Leibniz often and publicly highlights the success of the easiest path principle in optics, it does not represent his only strategy to defend final causes. He employs a suite of teleological principles in his natural philosophy, including conservation laws, the principle of the equality of cause and effect, and the principle of continuity, all of which he collectively labels "metaphysical" or "architectonic." ${ }^{11}$ These principles serve a variety of functions in his scientific work besides occasionally providing an alternative method of deduction. Architectonic principles play an essential role, for instance, in the unification of empirical laws, and in guiding hypothesis

\footnotetext{
${ }^{31}$ Leibniz indicates the equivalence of these terms in "On the Correction of Metaphysics and the Concept of Substance" (1694), where he describes metaphysics as the "primary and architectonic discipline" (GP IV 468; L 432). In early modern philosophical usage, "architectonic" connotes,

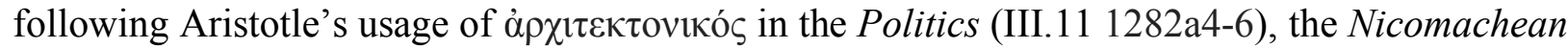
Ethics (I.1 1094a1-26), and the Physics (II.2 194a34-b8), a master science or art that supplies principles to a subordinate field in virtue of knowing the latter's goal of production. Aristotle's conception of an architectonic discipline as one that regulates and orders others, and for whose sake special disciplines are practiced, was alive in the seventeenth and eighteenth centuries. In his Lexicon of 1652, for example, Johann Micraelius notes Aristotle's extension of the classical, architectural sense of the term as scientia bene aedificandi, to the science of politics through which cities are properly ordered and governed. The idea of architectonic as the art of constructing intellectual systems becomes general in the eighteenth century, finding its most selfconscious expression in J.H. Lambert's Anlage zur Architectonic, oder Theorie des Einfachen und des Ersten in der philosophischen und mathematischen Erkenntniß (1771). Kant's notion of an "architectonic of pure reason" preserves this conception of a governing science of principles, which he identifies with his critique of the cognitive faculties.
} 
choice. In such theoretical functions we see a substantive interaction of teleology and mechanism. In general, while mathematical-mechanical laws express regularities between physical quantities of bodies, teleological laws stitch those laws together to represent nature systematically. While the content of physical science consists in its descriptive concepts and laws, the intelligibility of phenomena by means of this content depends on its being interpreted under principles of order.

Leibniz's defense of teleology is further rooted in considerations about the aim of science in general. He accepts on behalf of the new mechanical philosophy a classical conception of scientia as truth-directedness. Physical science, specifically, seeks the kind of truth proper to phenomena, or to what is composite, namely a stable order and regularity in the succession of appearances. The value of such knowledge, Leibniz emphasizes, is not mere utility such as could be exploited for external profit even while one remains in a state of ignorance about causes. The goal of inquiry rather is the "perfection of the mind itself," or the attainment of clarity and precision in one's knowledge so that, "if someone were to discover some admirable device of nature and to learn its mode of operation, he would have achieved something great even if no application of his discovery to common life could be shown." ${ }^{32}$ The perfection of the mind comes apart from a defense of physical science grounded in the practical advantages it affords. Leibniz thus rejects one contemporary current in the interpretation of the new science that regards at least some of its theoretical results as reflecting nothing more than the "Workmanship of Men," in Locke's famous phrase. ${ }^{33}$

\footnotetext{
32 "Praefatio ad libellum elementorum physicae", A VI.4 1994; L 280.

33 Locke (1975, III.vi.37).
} 
But, further, Leibniz does not conceive science as offering signs of God's particular volitions, as, for instance, Samuel Clarke maintained. For Clarke, matter being indifferent to purposeful powers and laws, "there is no such thing as what men commonly call 'the course or nature' or the 'power of nature'." Rather, "[t]he course of nature, truly and properly speaking, is nothing else but the will of God producing certain effects in a continued, regular, constant, and uniform manner." We certainly detect regularities in natural experience. But nature itself does not bear the causes, thus the explanatory grounds, of its regular appearances, which reside instead in a radically free, divine will. ${ }^{34}$ Against this voluntarist tradition in natural religion, Leibniz rejects attempts to locate the value of natural science in any suggestion of divine purposes as intimated by plant morphology or advantageous climate patterns. The intellectual perfection of the mind through scientific discovery brings joy or felicity, according to Leibniz, only because it provides insight into "the laws or the mechanisms of divine invention," that is, to the intelligible reasons behind natural patterns. ${ }^{35}$ Mechanical explanations, in other words, ought to be interpreted as partial expressions of the divine intellect, rather than of God's arbitrary volitions or of human purposes in controlling nature. Leibniz rehabilitates teleological principles precisely in service of a naturalistic interpretation of the new book of nature, and against approaches that would construe its hard-won fruit either as the expression of so many miracles, or as conventions instituted by self-interested human observers.

\footnotetext{
${ }^{34}$ Clarke, A Discourse Concerning the Unchangeable Obligations of Natural Religion, 1705 (1998, 149). Cf. Clarke's Second Reply to Leibniz, GP VII 359; L 680. Other notable figures in this tradition include John Ray and William Derham. Gascoigne (1989) speaks of a "holy alliance" between Anglican natural theology and Newtonian science at Cambridge at the turn of the century.

35 "Praefatio ad libellum elementorum physicae", A VI.4 1994; L 280.
} 
These teleological or architectonic principles anchor physics in metaphysics. Yet, it is important to bear in mind that, for Leibniz, such anchoring is only partial, so that physics cannot be deduced a priori from metaphysics. Empirical physics has, as he sometimes puts it, only moral certainty insofar as it concerns the coherence of perceptions. As he writes to Foucher in 1675 ,

The more consistency we see in what happens to us, it is true, the more our belief is confirmed that what appears to us is reality... This permanent consistency gives us great assurance, but after all, it will be only moral until somebody discovers a priori the origin of the world which we see and pursues the question of why things are as they appear back to its foundations in essence. ${ }^{36}$

The foundations of even the most well-confirmed physical laws lie in "essence," upon which even the kind of truth-orientation proper to phenomena depends. While this foundational, metaphysical project lies outside the legitimate bounds of physics, it nevertheless supplies principles which are assumed in the empirical investigation of nature, insofar as it aims to establish the truth expressed in well-founded phenomena. In a later text, "On the Method of Distinguishing Real from Imaginary Phenomena," Leibniz identifies further criteria for wellfounded, or real, as opposed to imaginary, or unreal, phenomena. These criteria include their congruity, complexity, coherence with past, regular phenomena, and our ability to give explanations for them. But the most important criterion, for Leibniz, is the harmony of perceptions within a perceiver's experience, as well as intersubjective agreement among different perceivers. Harmony also grounds the predictive order of perceptions, and it is highlighted as the most important mark that secures reality for phenomena: "the most powerful criterion, sufficient

${ }^{36}$ A II.1B 391; L 154. 
even by itself, is success in predicting future phenomena from past and present ones, whether that prediction is based upon a reason, upon a hypothesis that was previously successful, or upon the customary consistency of things as observed previously." ${ }^{37}$ Robert Adams comments on this important text: "Real phenomena are those that form part of a coherent, scientifically adequate story that appears all or most of the time, at least in a confused way, to all or most perceivers. That is the story that would be told, or approximated, by a perfected physical science. Imaginary phenomena are those that do not fit in this story." 38 Teleological principles enter empirical physics to anchor the study of real phenomena in metaphysics by supplying assumptions of their maximal harmony and unity. They dispense their function in a variety of ways.

Teleological principles enter, for instance, as premises in arguments to unify empirical laws, thus to increase their generality. A signal instance of this use occurs in Leibniz's unification of the laws of motion and rest by applying the principle of continuity. In effect, by conceiving motion as a continuous quantity Leibniz is able to treat rest as a limit case of motion. Assuming the motion of body A to remain constant, we vary continuously the quantity of motion of a second body B as it collides with A until the motion of B approaches zero at the moment of collision. This state is defined as rest, after which the motion of B increases continuously in the opposite direction as it rebounds. Likewise, in the case when B is at rest, the motion of A is described as a continuously changing quantity that merges with the quantity of motion of B as the bodies collide. Applying the law of continuity to colliding bodies thus allows Leibniz to treat rest as "the limit of the cases of directed motion, or the common limit of linear or continuous motion, and so, as it were, a special case of both." 39 In other words, the same law that governs

${ }^{37}$ GP VII 320; L 364.

38 Adams (1994, 257).

39 “Specimen dynamicum”, GM VI 250, L 447-8; cf. "Reply to Malebranche”, G III 52-3, L 352. 
velocity can be shown to apply to its absence, or rest. The principle of continuity enables greater unification among laws of nature by supporting idealizations - in this case, treating rest as infinitesimal or vanishing motion — under which discrete rules receive a common analysis. Leibniz, in this way, provides deeper foundations for an assumption already present in Galileo and Descartes, that motion and rest are simply different modes of bodies. ${ }^{40}$ As a foundational project, Leibniz takes this kind of unification to be not simply for the sake of cognitive economy but rather a guide to truth. While separate rules might adequately subsume unknown cases to known ones to facilitate prediction, their sufficiency for explanation remains an open question. The discovery of lawful connection of the phenomena of motion and rest under a single, more general rule now serves as a constraint on future theorizing. Subsequent analysis of the special cases should not lead to rules that violate the unity (or harmony) known to hold among them. In this regard, Leibniz shares with Aristotle before him, and with more recent philosophers of science since, a conception of scientific explanation as aiming not just at predictive success but also intelligibility. ${ }^{41}$

Considerations of unity and harmony also figure as reasons for choice between equivalent hypotheses. One of the most important of such choices in the seventeenth century is between geocentric and heliocentric cosmological models, around which debate intensified following the formal condemnations in 1616 and 1633 of Copernicus' De revolutionibus and of Galileo's

\footnotetext{
40 Galileo, Dialogues (1953, 20-1); Descartes, Principles Pt II, §27 (1982, 52).

41 "Specimen dynamicum", GM VI 250, L 447. Compare Herbert Feigl on unification as a virtue: "The aim of scientific explanation throughout the ages has been unification, i.e., the comprehending of a maximum of facts and regularities in terms of a minimum of theoretical concepts and assumptions" $(1970,12)$.
} 
advocacy of heliocentrism. ${ }^{42}$ A common defense of Copernicanism from Church censure following this storied affair exploited Galilean arguments for the relativity of motion. Just as an observer below the deck of a ship moving with uniform speed and direction would not be able to determine whether the ship was in motion or at rest by studying projectiles in her cabin, observers on Earth could never experimentally establish if the Sun or the Earth were in motion. But if true motions cannot be ascribed to bodies, neither the heliocentric nor the geocentric (nor, for that matter, Tycho Brahe's geoheliocentric) model could be shown to be the physically correct one on observational grounds. Copernicanism, therefore, should simply be treated as an alternative computational model, a mere calculational instrument that saves the astronomical data but cannot pretend to speak the truth, any more than the Tychonic model with its implausible intersection of the Sun's orbit with those of Mercury, Venus, and Mars. ${ }^{43}$ It thus could not offend against Joshua 10:12-14, because it leaves open a literal reading of Joshua's command to the Sun to stand still, according to this defense. ${ }^{44}$ Leibniz's interventions in the Copernicanism controversies in the 1680s and 1690s, while ultimately unsuccessful from a diplomatic point of view, reveal his commitment to cosmological teleology as a presupposition of scientific realism.

\footnotetext{
${ }^{42}$ For a recent study of defenses of Copernicus and Galileo in the seventeenth century, see Finocchiaro (2009). Rather less familiar is the diversity of scholastic defenses of geocentrism which seriously engaged heliocentric arguments. See Grant (1984) for a helpful corrective. ${ }^{43}$ To be sure, Tycho had important defenders in the seventeenth century, such as the Jesuit astronomer Giambattista Riccioli. In his monumental Almagestum Novum (1651), Riccioli defended a modified version of the Tychonic system, with its stationary Earth, and two separate centers at the Sun and the Earth, against both the Copernican and Ptolemaic. Riccioli's main targets were the justification of Galileo's condemnation, and a defense of a geostatic cosmology, for which he found the Tychonic model better on astronomical grounds. Leibniz, for his part, accepts both Galilean relativity and the hypothesis of a mobile Earth. In what follows, the contrast between the geocentric (and geostatic) versus the heliocentric models will be treated at a higher degree of abstraction, and will exclude the specific differences between the Tychonic and Ptolemaic models.

44 See Omodeo (2014) for a wide-ranging study of the reception of Copernicanism in the broader cultural and intellectual debates of the sixteenth and seventeenth centuries.
} 


\section{Copernican harmony as determination}

Unlike instrumentalist defenders of Copernicanism in the seventeenth century, Leibniz takes the empirical equivalence of the geocentric and heliocentric systems to invite reflection upon the criteria for ascribing true motion and rest. Taken as a description of physical reality, a (Galilean) relativistic analysis of motion in inertial frames leads to the unacceptable consequence that we can never assert whether a body is in motion or at rest. Leibniz, in fact, draws an even stronger conclusion: "if there is nothing more in motion than this reciprocal change [of mutual vicinity or position], it follows that there is no reason in nature to ascribe motion to one thing rather than to others. The consequence of this will be that there is no real motion." ${ }^{\prime 45}$ If it were impossible in principle to determine which of two bodies was in motion at any given moment, then ascriptions of motion could never be interpreted as having objective truth conditions. In the context of celestial mechanics, one would have to conclude that there is no fact of the matter as to whether the Sun moves or the Earth. Leibniz correctly recognizes the situation as one in which observational evidence will always underdetermine planetary theory, which results in his doctrine of equivalence of hypotheses:

As for absolute motion, nothing can determine it mathematically, since everything ends in relation. The result is always a perfect equivalence in hypotheses, as in astronomy, so that no matter how many bodies one takes, one may arbitrarily assign rest or some degree

45 “Animadversiones”, GP IV 369; L 393. See Lodge (2003) for a fuller analysis of Leibniz's argument for the relativity of motion. Garber $(2009,106-115)$ details the development of Leibniz's views on motion as relational. 
of velocity to any one of them we wish, without possibly being refuted by the phenomena of straight, circular, or composite motion. ${ }^{46}$

A physics restricted to mathematical-mechanical principles alone could not coherently claim to speak the truth or approximate truth about phenomena.

Rational principles enter here as normative criteria for deciding among competing theories. For Leibniz, the choice of the simpler or more intelligible theory is not merely a matter of convenience. As he writes to Huygens in 1694, given an equivalence of hypotheses, "when I assign certain motions to certain bodies, I do not have, and cannot have, any other reason but the simplicity of the hypothesis (other things being equal) for the true one." ${ }^{47}$ In Leibniz's use of simplicity as a criterion, we find an urgent concern to interpret the new science as advancing the truth about the physical world. Insofar as physics aims, as Leibniz insists it does, to uncover the truth about phenomena, it takes the regular motions of bodies to express a determinate, intelligible order. The Copernican attribution of rest to the Sun and motion to the Earth asserts that the actual Sun and the Earth instantiate the properties of rest and motion respectively; these are not merely convenient ways of speaking. But mathematical considerations alone are insufficient to ground such attributions, a conclusion Leibniz had already embraced in the 1670s. ${ }^{48}$ Thus, the natural philosopher must look elsewhere to settle the matter. The principle of simplicity supplies one such consideration and serves as a criterion to adjudicate between competing astronomical systems.

As discussed earlier, in physics Leibniz does not take simplicity as a guide to absolute or metaphysical truth. As Paul Lodge observes, in the exchange with Huygens as well as in the

\footnotetext{
46 "New System" G IV, 486-87, L 459.

${ }^{47}$ GM II 199; L 419.

${ }^{48}$ Garber $(2009,112)$.
} 
"Specimen Dynamicum," Leibniz is careful to qualify the appeal to simplicity with locutions such as that one can "hold" (tenir) the simplest hypothesis for the true one, or "we speak as the situation demands [loquimur, prout res postulat] in whatever way provides the more fitting and simpler explanation of the phenomena." 49 Absolute truth, for Leibniz, is not a notion pertinent to phenomena. Yet, while Lodge rightly cautions readers not to take Leibniz in these passages to be speaking of metaphysical truth, it must also be recognized that Leibniz does not take the empirical equivalence of hypotheses to amount to their epistemic equivalence tout court. Instead, he appeals to a different semantic notion, which he often calls "intelligibility," in physical matters. Indeed, he expressly identifies the truth of physical hypotheses with their intelligibility. ${ }^{50}$ Donald Rutherford explicates this restricted version of the principle of sufficient reason in the created world as "the principle of intelligibility [which] entails that whatever we assert of bodies, whatever laws we frame to describe their behavior, must be explainable in terms of the nature of body." ${ }^{51}$ That is, any quality actually possessed by a body has to be such that it can be explained by appeal to concepts proper to an analysis of bodies. Even though we cannot have demonstrative proofs of claims about corporeal phenomena as rendered in the empirical sciences - that is, claims about bodies cannot be reduced to identities in a finite number of steps through the principle of contradiction — we nonetheless possess rational criteria for adjudicating competing accounts. For Leibniz takes the intelligibility of a physical hypothesis to consist in the degree of distinctness it achieves in parsing concepts of phenomena. Intelligibility thus appears

\footnotetext{
49 Lodge (2003, 299-300); GM II 199; L 419; GM VI 248; L 445.

${ }^{50} \mathrm{C}$ 590-1; AG 91: "since... people do assign motion and rest to bodies, even to bodies they believe to be moved neither by a mind, nor by an internal impulse, we must look into the sense in which they do this, so that we don't judge that they have spoken falsely. And on this matter we must reply that the truth of a hypothesis is nothing but its intelligibility."

${ }^{51}$ Rutherford (1995, 241).
} 
as an in principle comparable quantity. In a suggestive note from 1700, Leibniz explicitly glosses intelligibility as a measurable, intersubjectively ascertainable notion: "reality should be evaluated according to the multitude and variety and order of things and thus, in a word, according to the quantity of intelligibility." 52

The notion of intelligibility lies at the root of Leibniz's opposition to instrumentalist or conventionalist defenses of Copernicanism. In a piece from 1689, written as part of his ultimately unsuccessful diplomatic efforts to have the Vatican's ban on the teaching of heliocentrism rescinded, he is clear that the empirical equivalence of various astronomical hypotheses does not license an arbitrary choice among them. His argument for allowing Copernicanism to be taught appeals to its philosophical merits. For, Leibniz writes, the Copernican hypothesis... displays the harmony of things at the same time as it shows the wisdom of the creator, and since the other hypotheses are burdened with innumerable perplexities and confuse everything in astonishing ways, we must say that, just as the Ptolemaic account is the truest one in spherical astronomy, on the other hand the Copernican account is the truest theory, that is, the most intelligible theory. ${ }^{53}$

Here, Leibniz tellingly distinguishes the values of the empirically equivalent geocentric and heliocentric systems. The former is certainly a good model for the computational purposes of positional astronomy. Traditional astronomy relied on data interpreted on the assumption of uniformly rotating spheres above an apparent plane surface, upon which technologies such as navigation charts, mariner's astrolabes, chronometers, and quadrants depended. Leibniz is aware

52 The text is edited and translated in De Risi (2006, 58-63).

${ }^{53}$ C 591-2; AG 92. Bertoloni Meli (1988, 25-9) establishes the context of this piece. Leibniz reiterates this position some years later as part of a general defense of the use of teleological principles in the "New System": "it is reasonable to attribute true motions to bodies if we follow the assumption which explains the phenomena in the most intelligible way" (GP IV 487; L 459). 
that the Ptolemaic model not only saves all the relevant data but also serves adequately the ends of seafaring. For a navigator, it makes little sense to abandon an intuitively plausible, empirically sufficient model, which furthermore supports a sophisticated array of instruments, almanacs, and shared practices. ${ }^{54}$

Yet, Leibniz declares the heliocentric theory to be the better physical theory on account of its greater intelligibility, and because "it displays the harmony of things." Now, Copernicus himself had highlighted harmonia as an important virtue of his model. Copernicus' conception of harmony has sometimes been understood in aesthetic terms. As Thomas Kuhn observes in his influential study, Copernicus recognized that "the real appeal of sun-centered astronomy was aesthetic rather than pragmatic... The ear equipped to discern geometric harmony could detect a new neatness and coherence in the sun-centered astronomy of Copernicus." ${ }^{55}$ But whether or not Copernicus' conception of harmony was aesthetic in the way it has been understood by Kuhn, among others, Leibniz seems to have drawn a different lesson from the achievement of heliocentric astronomy. For Leibniz, the greater harmony of Copernicus' model is a semantic feature, rather than an aesthetic one, or a pragmatic one. In other words, it is neither in virtue of its finer symmetry, nor in virtue of any practical success, but rather because of its greater truthaptness that heliocentrism is preferable to geocentrism. Specifically, the harmony of Suncentered astronomy consists in the determinacy which follows from its basic assumptions.

\footnotetext{
${ }^{54}$ In fact, even the construction of modern planetariums in the early twentieth century began by self-consciously emulating the Ptolemaic model in their use of gears and motors to simulate a uniformly rotating celestial sphere passing before a stationary observer. See Bigg (2017) for a case study of the construction of projection planetariums in interwar Germany. ${ }^{55}$ Kuhn $(1957,172)$. Copernicus emphasizes harmony and symmetry in Bk 1, Ch 10 of De revolutionibus: "So we find underlying this ordination an admirable symmetry in the Universe, and a clear bond of harmony in the motion and magnitude of the Spheres [Invenimus igitur sub hac ordinatione admirandam mundi symmetriam, ac certum harmoniae nexum motus et magnitudinis orbium]" (translation in Kuhn 1957, 180).
} 
Leibniz defines harmony in general as "diversity compensated by identity." ${ }^{56}$ Harmony is the property of unity in a multiplicity of things, or of uniformity in a manifold, as would be instituted by a rule or law. This ontological sense of harmony is expressed more clearly in a later letter to Wolff: "order, regularity, and harmony come to the same thing. You can even say that it is the degree of essence, if essence is calculated from harmonizing properties, which give essence weight and momentum, so to speak. ${ }^{, 57}$ Harmony as a property of a collection of objects can be measured or determined to be of a definite grade. More precisely, it is the property of a system, a collection of distinct objects unified under rules of order, which ground its true, structural features. The greater the order, regularity, or stability in a system of objects, the greater its “degree of essence." The harmony of a system, thus, is neither a matter of taste nor of practical utility, but pertains to its constitutive features. It is this sense of harmony that, I contend, Leibniz wants to highlight in his defense of Copernicanism. Two differences in how the heliocentric and geocentric models address astronomical phenomena illustrate this point.

The first example has to do with the problem of retrograde motion of the superior planets (Mars, Jupiter, and Saturn). At regular intervals, each of these planets appears to reverse its direction in the sky, briefly moving in the opposite direction from that of the other bodies in its system, before returning to its original direction. The Ptolemaic model accounts for these observations by placing the planet on a rotating epicycle, which itself is moved on a sphere, or, in a more minimalist model, on a circle called the "deferent." The resulting planetary path describes an epicycloid curve, the exact proportions of which vary according to the size and

56 "Harmoniam diversitatem identitate compensatam." Letter to Arnauld, November 1671, A II.1B 279; L 149.

57 “ordo, regularitas, harmonia eodem redeunt. Posses etiam dicere esse gradum essentiae, si essentia ex proprietatibus harmonicisi aestimetur, quae ut sic dicam faciunt essentiae pondus et momentum.” 18 May, 1715, LW 172; AG 234. 
speed of the epicycle. In this procedure, saving the observations from a stationary point on Earth requires separate constructions for each planet (see fig. 1 for a construction showing the retrogradation of Mars). These constructions agree in the fact that the epicycles for each planet complete one revolution each year. In the Ptolemaic system, this is a brute fact, required to save the phenomena but having no physical basis.

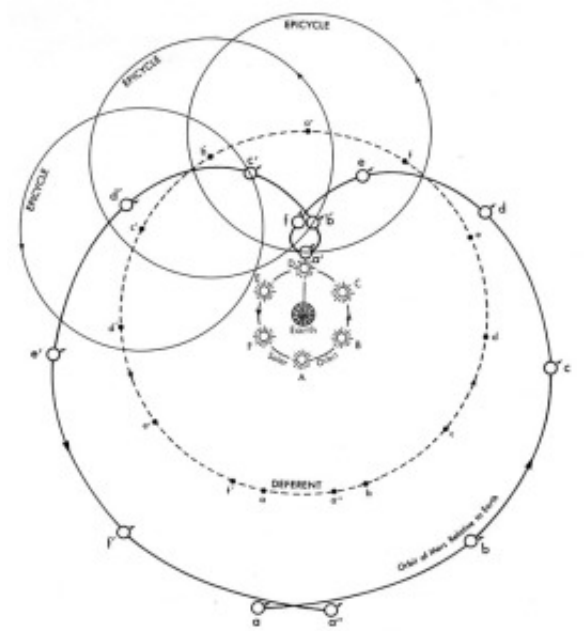

Fig. 1. Retrograde motion of Mars, in the Ptolemaic system

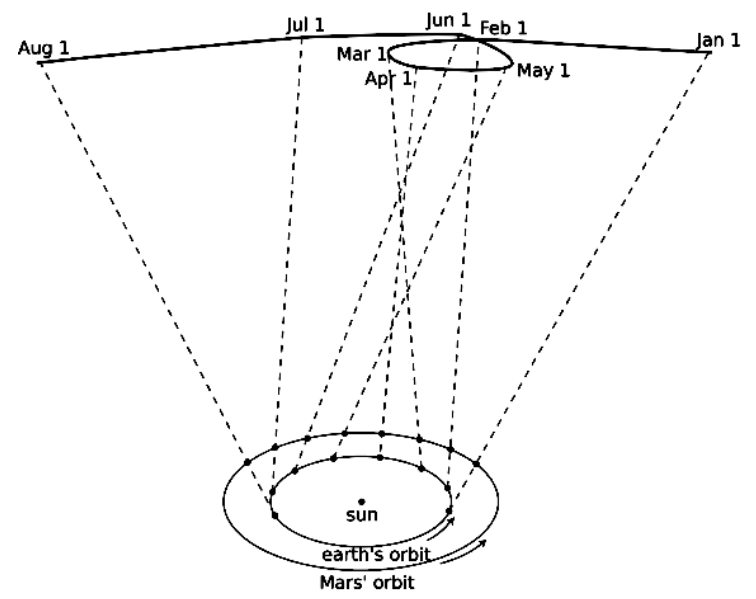

Fig. 2. Retrograde motion of Mars, in the Copernican system (Source: B. Crowell, 2005, www.lightandmatter.com)

By contrast, in the Copernican model, retrogradation of all the planets is explained as a natural consequence of the initial assumptions about the geometry of the system, namely, that the sphere of the stars is fixed, that the Earth moves around the Sun, and the Moon around the Earth. The retrograde transit of the superior planets follows from the fact that the Earth travels faster in its orbit around the Sun than do Mars, Jupiter, and Saturn. As a result, it is to be expected that, as the Earth overtakes Mars, for instance, Mars would appear to slow its eastward motion among the stars, briefly appear to move westward, and then resume its original direction (see fig. 2). The 
fact of the annual revolution of the Earth about the sun also explains the yearly cycle assigned, in the Ptolemaic system, to the superior planetary epicycles. Further, besides furnishing a single reason for the retrogradations of the superior planets, the geometry of the model also determines precisely the size and order of the planetary orbits, once the frequency of retrograde transits is established. The exact order of the planets was a question on which the Ptolemaic astronomy had always remained ambivalent; Copernicus' model posits a determinate order on the basis of specific geometrical reasons.

A second astronomical problem relates to a peculiarity in the appearance of the inferior planets, namely, that these never wander very far from the Sun. The Ptolemaic solution for the apparent proximity of Mercury and Venus to the Sun was to tie the centers of the epicycles of the three bodies together so that they rotate around the Earth in sync. Differences in the sizes of Mercury's and Venus's epicycles, meanwhile, model their different relative positions in the sky (see fig. 3). The construction adequately saves the phenomena only by introducing an arbitrary element — a chord binding the bodies to Earth — absent elsewhere in the system.
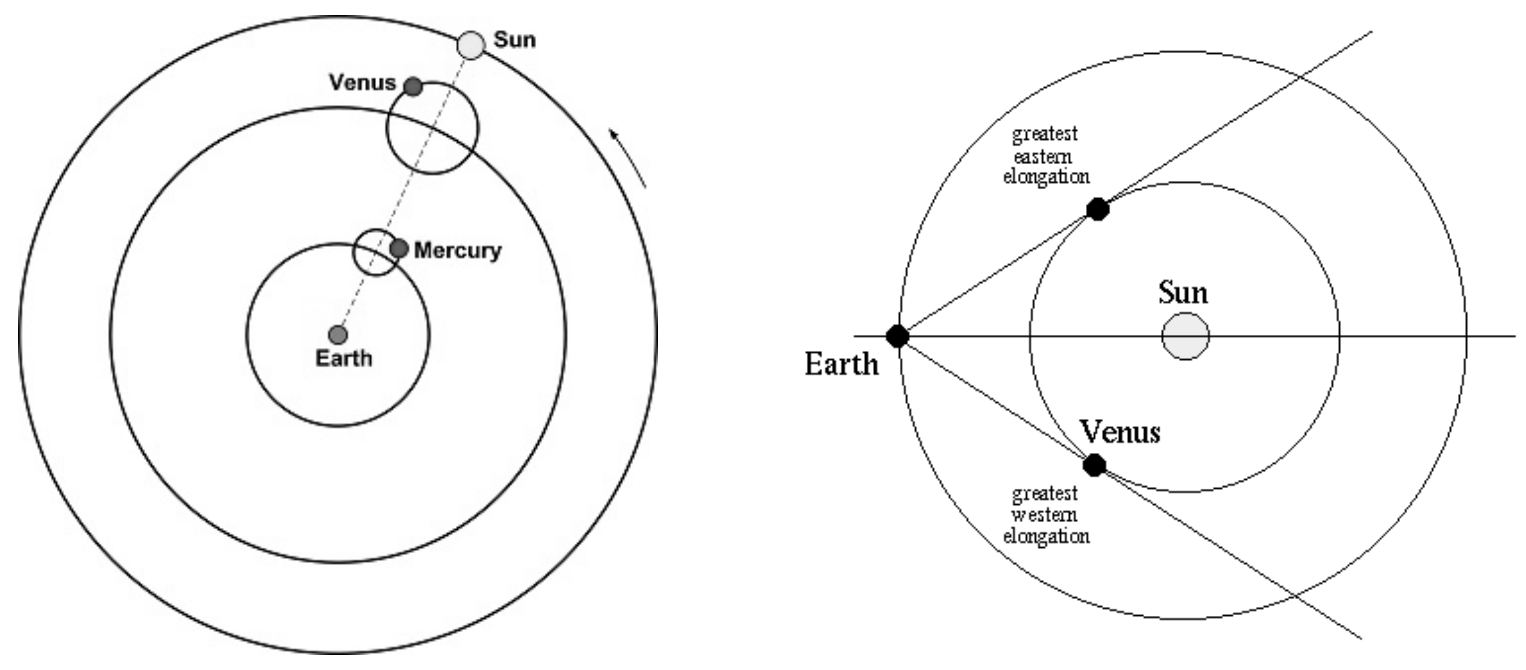
Fig. 3. Elongations of Mercury and Venus from the Sun, in the Ptolemaic system
Fig. 4. Elongations of Mercury and Venus from the Sun, in the Copernican system (Source: George Benthien, www.gbenthien.net)

Sun-centered astronomy, by contrast, does not need recourse to special elements to explain this fact. Once again, the apparent proximity of the inferior planets to the Sun is a necessary consequence of the basic geometrical scheme. Given their positions between the Earth and the Sun, it is to be expected that Mercury and Venus would always appear within a narrow band from the Sun's path, because their elongation from the Sun as observed from Earth would always be limited by their smaller orbits relative to Earth's (see fig. 4). As with the problem of retrograde motion, these facts are also determined by a more general feature of the model, rather than requiring a special solution.

Thus, what recommends acceptance of heliocentrism with a mobile Earth as the better physical theory is what Leibniz calls its greater harmony, or its determination of diverse phenomena under fewer rules. Sun-centered astronomy reduces arbitrariness in its models, so that fewer initial assumptions are sufficient to explain a wider range of qualitative phenomena. Neither pragmatic nor aesthetic considerations speak especially in favor of Copernicus' scheme. On the one hand, the old, positional astronomy remained the preferred option on practical grounds in virtue of being embedded in cultures of material technologies and practices. On the other, Copernicus' final scheme retained much of the ontological complexity for which later generations would disparage Ptolemaic astronomy — for instance, while doing away with the major epicycles with annual periods, Copernicus re-introduced an equivalent number of smaller epicycles in saving the phenomena. Rather, it is on theoretical grounds that heliocentrism is to be 
preferred, for it institutes greater order in the phenomena, and hence contributes to the perfection of the mind.

Finally, the greater determination internal to heliocentric planetary astronomy also makes it amenable to unification with physical science, thus to a kind of inter-theoretic convergence that likewise supplies positive reasons of harmony. Leibniz regards the possibility of the convergence of heliocentrism with advances in kinematics as a reason for holding it to be true. In 1689, Leibniz published his response to Newton's Principia, the Tentamen de motuum coelestium causis, in which he took an important step in the direction of unifying mechanics with Kepler's elliptical model of planetary motion. Following the models of Descartes and Huygens, Leibniz hypothesizes a fluid, mechanical ether as a vehicle for the propagation of moving force by appeal to properties of shape, size, and velocity. A plenist model offers a mechanical theory by which impulsions in a physical medium could maintain the planets in harmonic circulation, as required by Kepler's laws. While Leibniz is certainly aware that experimental evidence is lacking for both the elliptical astronomy and the mechanical ether, he nonetheless hopes with this work to "come close to the true causes of celestial motions." ${ }^{58}$ As he regards it, the new astronomy first makes possible a physical-mechanical account of celestial motion, and thus takes a step toward the ultimate end of a unified representation of nature. ${ }^{59}$

The upshot of this convergence of astronomical and physical theory finds its way in Leibniz's diplomatic endeavors. Touting the advantages of theoretical unity, he writes:

\footnotetext{
${ }^{58}$ Bertoloni Meli (1993) gives a translation of the text in GM VI 144-161 and a commentary on its genesis and significance.

${ }^{59}$ In another, related text from the same year, "Tentamen de Physicis motuum coelestium Rationibus," Leibniz expresses hope for the possibility of being able to "explain the physical causes of planetary motion" (A VI.4C 2041).
} 
For not only do the labyrinths concerning the stations and retrograde motions of the planets disappear with one mental stroke... but magnetic observations [of Jupiter's and Saturn's moons] are also united in a marvelous way since the Earth itself is like a magnet, not only with respect to the magnets of everyday experience, but also with respect to the heavenly bodies themselves... Copernicus could hardly have hoped for any greater confirmation of his view. ${ }^{60}$

In sum, Leibniz's advocacy of heliocentrism does not reflect an ecumenical proclivity to give Ptolemy, Copernicus, and the Church their dues, as some scholars have suggested. ${ }^{61}$ As Leibniz discusses the matter in the New Essays, since the time of the initial condemnations of Galileo, when the papal authorities believed geocentrism to be in conformity with both reason and scripture, "people have become aware that reason, at least, no longer supports it." ${ }^{62}$ By the 1690 s, in fact, there is a gathering sense among European intellectuals that, despite the lack of conclusive experimental evidence, heliocentrism and the hypothesis of a mobile Earth has won the day against its detractors. ${ }^{63}$ Leibniz can thus mount a different response to the censure of Copernicanism than one which simply apportions equal share to the claims of reason and faith. For Leibniz, Church opposition to Copernicanism is not just dialectically inadequate, but epistemically problematic. It obstructs the dissemination of a superior physical theory, one that makes stronger claims to assent on account of its greater determinacy. In contrast to

\footnotetext{
${ }^{60}$ C 592-3; AG 93.

${ }^{61}$ Bertoloni Meli $(1988,27)$, for instance, interprets Leibniz here as an "equilibrist". 62 NE 515.

${ }^{63}$ In his Système de Philosophie, the Cartesian, Pierre Sylvain Regis, for instance, concludes his responses to the standard objections to the Earth's mobility as follows: "the hypothesis of the mobility of the Earth, which is now so common that it can be asserted that between all the various opinions which are found in Astronomy, it has more supporters, not only than any other, but even than all others together" $(1691,226)$.
} 
instrumentalist apologies for Copernicanism, Leibniz's intervention in the debate underscores his commitment to taking the claims of the best scientific theories at face value. As in the case of explanatory unification, his case for a realist interpretation of Copernicanism requires positing a criterion of truth that cannot be specified entirely in terms of observational evidence. Truth (or intelligibility) conditions for theoretical statements come apart from verification conditions.

\section{Teleology and the new science}

I have highlighted an epistemological role for teleological principles in Leibniz's physics as stemming from a concern to uphold scientific realism. While Leibniz deploys teleological reasoning in a variety of contexts, the valuable lesson is not the one conveyed in his claim that non-causal principles yield complete and adequate alternative explanations of physical phenomena. Teleological principles do not underwrite a separate series of laws parallel to those of mechanical physics, as Leibniz's optical writings at first suggest. Rather, the deep lesson is that non-causal considerations - teleological, metaphysical, or architectonic, in Leibniz's various locutions - are implicated in any representation of nature that purports to track the truth or approximate truth about its appearances. Principles of harmony or intelligibility are cognitively significant insofar as a realistic attitude about our knowledge-making practices brings with it a commitment to determinate reasons underwriting our claims about nature, or, conversely, to excluding the possibility that our investigations might be in vain. Classical teleological principles of nature's intrinsic orderliness get redeployed here as coherence-making features of our epistemic practices. A sentiment akin to Leibniz's insistence that, "besides purely mathematical

principles subject to the imagination, there must be admitted certain metaphysical principles, "'64

${ }^{64}$ GM VI 242; L 441. 
has found echoes in recent work on the limits of empiricist philosophies of science. Metaphysical reasons, as a number of recent authors have observed, are always at work in scientific practice to give precise meanings to theories and models. Criticizing a false dichotomy between metaphysics and empirical science, Anjan Chakravartty writes that, it is not metaphysics that empiricists should oppose, but degrees of metaphysical speculation that fall outside the bounds of what they judge to be appropriate to the forms of empirical inquiry that most interest them, in accordance with their epistemic and other values. Indeed, were they to oppose metaphysics simpliciter, it appears that they would be guilty of pragmatic incoherence, since they themselves generally rely on some such speculations in one form or another. ${ }^{65}$

It is logically possible, of course, for the world to be a dappled mosaic, or for nature to be fundamentally unknowable, so that any amount of metaphysical speculation would be equally in vain. But then the burden of proof falls on the dogmatic proponents of a disorderly nature to substantiate their claim, or on the skeptics who would cast doubt on the possibility of knowledge. For Leibniz, the epistemic attitude proper to the scientific enterprise, supported by the gathering successes of seventeenth-century research, is the optimistic one.

To be sure, there is a crucial theological dimension to Leibnizian optimism, which undoubtedly weighs heavily in his thinking and cannot be ignored. In brief, his thesis that the human mind is made in the divine image supplies the ultimate guarantee that human inquirers could glimpse some of the truth about God's creation. A wise, benevolent God would not only

\footnotetext{
${ }^{65}$ Chakravartty $(2007,206)$. Expressing a similar thought, William Bechtel $(1986,40)$ casts the rationalist element in science as teleological, inasmuch as it conveys the explanatory aims of science: "All science is implicitly teleological, insofar as it adopts a semantics for its models-it doesn't let every activity or process in a target system enter into its model, but picks those it deems as causally relevant to explain the phenomenon."
} 
construct the order of nature in such way as to exclude fundamental indeterminacies, but would also ensure that his moral subjects have the capacity to grasp enough of that order to appreciate his wisdom. ${ }^{66}$ Leibniz's anchoring of the truths of nature in God's intellect is importantly different from competing, voluntarist theologies in his time, and directly relevant to his realism about physics. The Newtonian strategy, or even that of some Cartesians, to integrate the new physics in a theistic worldview, as Leibniz never tires of complaining, turns nature into a realm of perpetual miracles in the form of divine interventions to preserve order. In treating nature as essentially indifferent to form and order and, therefore, in need of periodic divine assistance for its regularities, such approaches evacuate the natural world of any intrinsic facts of the matter about why certain laws hold rather than others, or why certain powers are suitable means for specific effects. For the Cartesian occasionalists and the Anglican natural theologians, every empirical discovery indicates an arbitrary divine volition, but not a fact about nature itself.

On Leibniz's view of God's relation to the world of experience, by contrast, empirical investigation ought to be regarded as a source of insight into reasons of natural order. Indeed, when properly conjoined with metaphysical principles, empirical inquiry should lead to the same reasons which guided God in the creation. Even though the contents of perception are not the fundamental constituents of reality (that title is reserved for Leibniz's monads), a rational divinity would ensure that a definite, intelligible order appears to created minds. Leibniz sums up the epistemological upshot of his image of God thesis in a letter to Damaris Masham:

[S]ince our understanding comes from God, and should be considered a ray of that Sun, we should conclude that what best conforms with our understanding (when we proceed

\footnotetext{
${ }^{66}$ See Jolley (2005) for a systematic interpretation of Leibniz centered on the thesis of human subjects as mirrors of God.
} 
methodically, and in accordance with the nature of the understanding itself) will conform with the divine wisdom; and that by following that method, we are following the procedure which God has given us. ${ }^{67}$

In understanding the order of nature, however partially, we access the same reasons that inclined divine wisdom to create the best of all possible worlds. Teleological principles underlie Leibniz's reconstruction of the new scientific worldview: when properly understood, the new science offers a vision of nature as a fully intelligible domain, requiring no divine assistance beyond its initial formation.

\section{Abbreviations of Leibniz's texts}

A Sämtliche Schriften und Briefe. 1923-. Edited by Berlin-Brandenburgische Akademie der Wissenschaften and Akademie der Wissenscaften zu Göttingen, Berlin: de Gruyter. (Cited by series, volume, and page)

AG Philosophical Essays. 1989. Edited and translated by Roger Ariew and Daniel Garber. Indianapolis: Hackett.

C Opuscules et fragments inédits de Leibniz: extraits des manuscrits de la Biblothèque Royale de Hanovre. 1903. Edited by Louis Couturat. Paris: Felix Alcan.

GP Die philosophischen Schriften, 7 vols. 1875-1890. Edited by C.I. Gerhardt. Hildesheim: George Olms. (Cited by series, volume, and page)

GM Leibnizens mathematische Schriften. 1849-1863. Edited by C.I. Gerhardt. Berlin: A. Asher \& Comp. (Cited by series, volume, and page)

L Philosophical Papers and Letters. 1969. Edited and translated by Leroy E. Loemker. Dordrecht: Kluwer.

LS The Leibniz-Stahl Correspondence. 2016. Edited and translated by Justin E.H. Smith and Francois Duchesneau. New Haven: Yale University Press.

LW Briefwechsel zwischen Leibniz und Christian Wolff. 1860. Edited by C.I.

${ }^{67}$ GP III 353; WF 211. 
Gerhardt. Halle: H.W. Schmidt.

NE New Essays on Human Understanding. 1996. Edited and translated by Peter Remnant and Jonathan Bennett. Cambridge: Cambridge University Press.

UP "Unicum opticae, catoptricae et dioptricae principium". 1682. Acta eruditorum, 1:185-190. Translated by Jeffrey McDonough. http://philosophy.ucsd.edu/faculty/rutherford/Leibniz/unitary-principle.htm.

WF Leibniz's 'New System' and Associated Contemporary Texts. 1997. Edited and translated by R.S. Woolhouse and Richard Francks. Oxford: Clarendon Press.

\section{References}

Adams, Robert Merrihew. 1994. Leibniz: Determinist, Theist, Idealist. New York: Oxford University Press.

Antognazza, Maria Rosa. 2017. "Philosophy and Science in Leibniz." In Tercentenary Essays on the Philosophy and Science of Leibniz, edited by Lloyd Strickland, Erik Vynckier, and Julia Weckend, 19-46. Palgrave MacMillan.

Aristotle. 1984. The Complete Works of Aristotle. Edited by Jonathan Barnes. Princeton, NJ: Princeton University Press.

Baker, Alan. 2009. "Mathematical Explanation in Science." British Journal for the Philosophy of Science 60: 611-33.

Bechtel, William. 1986. "Teleological Functional Analyses and the Hierarchical Organization of Nature." In Current Issues in Teleology, edited by Nicholas Rescher, 26-48. Lanham, MD: University Press of America.

Bertoloni Meli, Domenico. 1988. "Leibniz on the Censorship of the Copernican System." Studia Leibnitiana 20, 1: 19-42.

-1993. Equivalence and Priority: Newton versus Leibniz. Oxford: Oxford University Press.

Bigg, Charlotte. 2017. "The View from Here, There and Nowhere? Situating the Observer in the Planetarium and in the Solar System." Early Popular Visual Culture 15, 2: 204-26.

Buchdahl, Gerd. 1969. Metaphysics and the Philosophy of Science. Cambridge, MA: MIT Press.

Chakravartty, Anjan. 2007. "Six Degrees of Speculation: Metaphysics in Empirical Contexts." In Images of Empiricism, edited by Bradley Monton, 183-208. Oxford: Oxford University Press. 
Clarke, Samuel. A Demonstration of the Being and Attributes of God and Other Writings. Edited by Ezio Vailati. Cambridge: Cambridge University Press, 1998.

Darrigol, Olivier. 2012. A History of Optics. Oxford: Clarendon.

De Risi, Vincenzo. 2007. Geometry and Monadology: Leibniz's Analysis Situs and Philosophy of Space. Basel: Birkhäuser.

. 2006. "Leibniz around 1700: Three Texts on Metaphysics." The Leibniz Review 16: 5569.

Descartes, René. 1982. Principles of Philosophy. Translated by Valentine Rodger Miller and Reese P. Miller. Dordrecht: Kluwer.

Duchesneau, François. 1993. Leibniz et La Mèthode de La Science. Paris: Presses Universitaires de France.

Feigl, Herbert. 1970. “The 'Orthodox' View of Theories: Remarks in Defense as Well as Critique.” In Minnesota Studies in the Philosophy of Science, Volume IV, edited by M. Radner and S. Winokur. Minneapolis: University of Minnesota Press.

Finocchiaro, Maurice A. 2009. Defending Copernicus and Galileo. Dordrecht: Springer.

Galilei, Galileo. 1953. Dialogues Concerning the Two Chief World Systems. Berkeley and Los Angeles: University of California Press.

Garber, Daniel. 1985. "Leibniz and the Foundations of Physics: The Middle Years." In The Natural Philosophy of Leibniz, edited by Kathleen Okruhlik and James Robert Brown, 27130. Dordrecht: Reidel.

. 2009. Leibniz: Body, Substance, Monad. Oxford: Oxford University Press.

Gascoigne, John. 1989. Cambridge in the Age of the Enlightenment. Cambridge: Cambridge University Press.

Ginzburg, Lev, and Mark Colyvan. 2004. Ecological Orbits: How Planets Move and Populations Grow. Oxford: Oxford University Press.

Grant, Edward. 1984. "In Defense of the Earth's Centrality and Immobility: Scholastic Reaction to Copernicanism in the Seventeenth Century." Transactions of the American Philosophical Society 74, no. 4: 1-69.

Gueroult, Martial. 1967. Leibniz: Dynamique et Métaphysique. Paris: Aubiers-Montaigne.

Hartz, Glenn A. 2007. Leibniz's Final System: Monads, Matter, and Animals. Oxford: Routledge. 
Jolley, Nicholas. Leibniz. New York: Routledge, 2005.

Kuhn, Thomas. The Copernican Revolution. Cambridge, MA: Harvard University Press, 1957.

Lange, Marc. 2013. "What Makes a Scientific Explanation Distinctively Mathematical?" British Journal for the Philosophy of Science 64(3): 485-511.

Lemons, Don S. 1997. Perfect Form. Princeton, NJ: Princeton University Press.

Locke, John. 1975. An Essay Concerning Human Understanding. Edited by Peter Nidditch. Oxford: Clarendon. (cited by book, part, and paragraph number)

Lodge, Paul. 2003. "Leibniz on Relativity and the Motion of Bodies." Philosophical Topics 31: 277-308.

Mach, Ernst. 1919. The Science of Mechanics. 4th ed. Translated by Thomas J. McCormack. Chicago: Open Court.

McDonough, Jeffrey. 2008. "Leibniz’s Two Realms Revisited.” Nous 42 (4): 673-96.

_ 2009. "Leibniz on Natural Teleology and the Laws of Optics." Philosophy and Phenomenological Research 78 (3): 505-44.

_. 2010. "Leibniz's Optics and Contingency in Nature." Perspectives on Science 18 (4): $432-55$.

- 2016. "Leibniz and the Foundations of Physics: The Later Years." Philosophical Review 125 (1): $1-34$.

McRae, Robert. 1976. Leibniz: Perception, Apperception, and Thought. Toronto: University of Toronto Press.

Micraelius, Johann. 1653. Lexicon philosophicum terminorum philosophis usitatorum. Jena: Jeremiah Mamphras.

Okruhlik, Kathleen. 1985. "The Status of Scientific Laws in the Leibnizian System.” In The Natural Philosophy of Leibniz, edited by Kathleen Okruhlik and James Robert Brown, 183206. Dordrecht: Reidel.

Omodeo, Pietro Daniel. 2014. Copernicus in the Cultural Debates of the Renaissance. Leiden: Brill.

Phemister, Pauline. 2005. Leibniz and the Natural World: Activity, Passivity, and Corporeal Substances. Dordrecht: Springer. 
Psillos, Stathis. Scientific Realism: How Science Tracks Truth. London and New York: Routledge, 1999.

Regis, Pierre Sylvain. 1691. Système de Philosophie, Volume 3. Lyon: Anisson, Posuel, \& Rigaud.

Rutherford, Donald. 1995. Leibniz and the Rational Order of Nature. Cambridge: Cambridge University Press. 